\title{
The Analysis of Kindergarten Teachers' Professional Happiness
}

\author{
Yang Zhongyan \\ Feixian Campus, Linyi University \\ Linyi, Shandong, China \\ fxsfyzy@126.com
}

\begin{abstract}
The professional happiness is an important content of the assessment of the professional development of preschool teachers. It is an important indicator of measuring the quality of early childhood education. The analysis of preschool teachers' sense of well--being is conducive to enhancing the social recognition for preschool teachers, and it also serve the need of development of the preschool teachers and preschool education. Based on the analysis of the concept of preschool teachers' professional happiness and the meaning of research, the paper analyzes the causes of influencing preschool teachers' professional happiness and explores the ways to promote preschool teachers' professional happiness.
\end{abstract}

Keywords- Kindergarten Teachers; Professional Happiness; Reason; Ways; Analysis

\section{THE KINDERGARTEN TEACHERS' PROFESSIONAL HAPPINESS}

Mr. Xia Gaizun, the famous educator of China, once said: "the educator's emotion and love are like the water in the pond. Not water, no pound. No emotion and love, no education." That is to say, emotion is very important for education. There are emotions of many kinds, and happiness is one of them.

Happiness has always been a people's pursuit of the eternal topic. Only people who feel happy are happy and sunshine. People have the right to pursuit happiness, regardless of race, region, occupation, age, gender, etc. Different people have different understanding about happiness. Some people think that happiness is a kind of feeling that comes naturally and easily and can't be demanded. Some people think that happiness is having a pure, healthy and harmonious life.

When we say happiness, we mean a healthy and happy living condition. It is a kind of subjective feeling. It is also known as subjective well-being. It makes the subject produce the feeling of joy and harmony. People's needs are diverse, and happiness is also varied.

Professional happiness is a subjective feeling that people get in the process of work. Teachers' professional happiness includes both external and internal happiness. External professional happiness refers to the teacher as an education workers have to undertake social responsibilities, obligations, mission, and the actual social contribution. It is the teacher professional basis and the basic way to realize own value. Internal professional happiness refers to the teachers' value and significance, as a profession. It includes rights, benefits, status and degree of self development and spiritual freedom teachers share in the social system and professional system. Teachers' professional happiness is an important index measuring teachers' quality of working and life, promoting teachers' professional development, and improving the quality of education. Paying attention to teachers' professional happiness is beneficial to promote the development of teachers and improve the teachers' quality of life. It is also advantageous to the student's healthy growth and development.

The preschool teacher's occupational happiness sense is also preschool teachers' subjective happiness sense. It refers to a pleasurable experience gained by the preschool teachers, by individual or in groups, in early childhood education practice and teaching through their own efforts from the work. The sense of professional happiness is an important prerequisite to work well for kindergarten teachers and the motive force to develop the profession. It concerns not only kindergarten teachers themselves but also the development of infant's health and early childhood education.

\section{THE RESEARCH SIGNIFICANCE OF PRESCHOOL TEACHERS' PROFESSIONAL HAPPINESS}

First, the study of preschool teachers' professional happiness can provide preschool teachers a chance to express their own opinions, reduce their grumble and complain, and make preschool teachers constantly reflect on and summarize themselves, which can make preschool teachers fall in love with themselves and their work.

Second, Mr. Ye Lan once said: "There is no high quality of education without teachers' high quality of life. There is no students' spiritual liberation without teachers' spiritual liberation. There is no student's initiative development without teacher's initiative development". Research on preschool teachers' professional happiness can cause the kindergarten teachers and their professional quality of life to the attention of society, which attaches importance to the improvement of life quality preschool teachers' and ultimately improves the quality of early childhood education.

Third, according to the study of preschool teachers' professional happiness, it can be seen that society and parents are both the important aspects to affect kindergarten teachers' professional well-being. Based on the analysis, we can see the parents' attitude, and cooperation degree and preschool teachers' social status have important influence on preschool teachers. It is helpful for parents and teachers to foster children and carry out social work.

Fourth, the study of preschool teachers' professional happiness can provide effective theoretical basis and guidance for education department to make educating and teaching management method, for normal universities to 
undertake teachers training, for the kindergarten to manage teachers.

\section{AN ANALYSIS OF THE CAUSES OF INFLUENCING THE PROFESSIONAL HAPPINESS OF KINDERGARTEN TEACHERS'}

At present, the happiness experienced in the work for kindergarten teachers is not high. Mainly, the reasons are as follows.

\section{A. The Overall Low Social Status}

Social status refers to the position of the people in the social structure of the system. There are a lot of factors that determine people's social status. "In the modern industrial society, the level of people's social status depends on how much social resources they have. The so-called social resources generally refer to four aspects - wealth, power, prestige, knowledge and skills. The greater people have the amount of these resources, the higher their social status." Amano Kaoruo said. We can see that when people measure a person's social status, the basic elements such as economic income and professional reputation are always related.

(1) Income

A survey of Guiyang city shows that the income of preschool teachers is directly proportional to their happiness. Generally speaking, the higher the income is, the higher the sense of happiness. At present, preschool teachers' income is generally not high in our country. Take Linyi City for example, in 2014, in Linyi City, the average wage was 4187 yuan. But the average wage of kindergarten teachers' is less than 2000 yuan. Such income situation seriously affects the happiness of preschool teachers'.

(2) Occupational Prestige

Dongchangfu District, Liaocheng City, Shandong province has done a survey about preschool teachers' professional prestige. The result shows that in 30 professional reputation, university teachers, secondary school teachers, primary school teachers, preschool teachers were the 2nd, 8th, 13th and 17th. From this we can see that compared with other levels of teachers, preschool teachers' professional prestige is not high, which also affects the cultivation of their professional happiness.

\section{B. Unreasonable "Infant--Teacher Ratio"}

For children of 3-6 years old, their physical and mental development is not complete. They can not take care of themselves independently in the kindergarten. Teachers need to control and guide their learning, living, and so on. This determines the preschool education is a complex social work. Kindergarten teachers need not only to take care of infants' daily life, but also to be responsible for their education and safety. Great responsibility requires a reasonable infant--teacher ratio. However, at present, in our country, the ratio is not reasonable in a lot of kindergartens. In most of kindergartens, there are much more students, and fewer teachers. This makes teachers' workload heavy, and teachers cannot take care of every child, and parents' satisfaction decrease. All of these aspects bring great pressure on preschool teachers. In addition, preschool teachers must deal with problems happened in the game or class in time. They are required to look after students with great care all the time in case some accidents happened. All of these will seriously affect preschool teachers' sense of happiness.

\section{PARENTS' NOT Understanding AND LEADERS' NOT SUPPORTING}

Now many parents see their children as babies. There are so many students in the kindergarten, some small frictions are inevitable, and sometimes a negligence of preschool teachers' may cause some problems. And if there are problems, parents always don't understand teachers or communicate with them, but directly complain to the heads of the kindergartens, which not only greatly hurt the teacher's feelings, also cause a misunderstanding between kindergarten teachers and parents. In addition, a lot of kindergartens place the parents' satisfaction and the safety of the infants above else, so some parents' complaints sometimes make the contradiction of teachers and the kindergarten leaders, which will also lead to a decrease of preschool teachers' sense of professional happiness.

\section{Preschool Teachers' Low Professional Level and Inaccurate Self-Position}

The professional degree of preschool teachers has an important influence on their happiness. Generally speaking, the higher the kindergarten teachers' degree of specialization, the richer they master professional knowledge of Education Science, psychology, behavioral science and so on. It means they have higher professional qualities and professional skills, and they can perform and definite their roles more accurately, and they can much more understand their profession. All of these are in favor of the formation of happiness. However, some unhappy things that preschool teachers abuse children in school occurred frequently, and the team of preschool teachers are not stable, and their educational background is deficient. All these prove that kindergarten teachers' degree of specialization is not high in our country. Some teachers cannot definite their roles accurately, which also affect the teachers' sense of happiness.

\section{E. Heavy Workload}

Workload has now become the main difference between kindergarten teachers and primary and secondary school teachers' professional happiness. Kindergarten teachers face 3-6 years old children, which requires them to combine caring and teaching in the work. Not only do they always put safety as the first to ensure children's security, but also they should exert positive effects on children's good behavior habits. In addition, there is a lot of work to do in the kindergarten. They need to prepare classes, have classes and prepare all kinds of activity materials. At the middle and end of the semester, they should hand in education notes, reflection and listening experience. They need to attend all kinds of training and meetings, write term and monthly plans, and design educating and teaching activities every day. Also, they need to watch children for a long time to learn children. So that they can prepare materials and organize activities, basing on the children's interests and needs to help children develop good habits and study habits. Therefore, heavy work has seriously affected their career happiness. Besides, teachers are in a living conscience. This intangible continuation adds to their workload, which let them feel 
that they are working all the time. In such a high pressure environment, it is easy to cause the teachers' professional happiness fade away.

\section{THE ANALYSIS OF WAYS TO IMPROVE THE TEACHERS' PROFESSIONAL HAPPINESS}

\section{A. Pay More Attention to Preschool Education and} Improve the Social Status of Kindergarten Teachers

Many people in the society do not attach importance to preschool education and kindergarten teachers, and the income of kindergarten teachers' is not high, so the kindergarten teachers' social status is low and their professional happiness decline constantly. Therefore, the state should attach more importance to the preschool education, and improve the social status of kindergarten teachers' continuously, increase their income, make them understood and respected by the society. Only in this way can the kindergarten teachers get a stronger sense of professional happiness.

First, the society should provide legislative guarantee for early childhood education. Pre-school education law should be produced as soon as possible. Preschool teachers should be provided with sacred duty. The social status of preschool teachers needs to be improved. All these can ensure that preschool children education to develop healthily in the paths of legalization and standardization. At the same time, the government and the education administrative departments at all levels should take emphasis on early children education, Standardize the management system of kindergartens, take efforts to make kindergarten education be included in the scope of the compulsory education, improve the status of preschool teachers, increase investment to early childhood education, high the level of kindergarten education and increase the preschool teachers' wages. In addition, the whole society should understand the characteristic of combination of caring and teaching, pay more attention to teachers, reduce teachers' occupational stress and improve their professional happiness.

The whole society should build a good atmosphere of public trust for preschool teachers and make the whole society respect teachers, especially the preschool teachers, which make preschool teachers have higher self-esteem and consider educating children as a sacred profession. Only in this way can their cause be more pursuit and they are easier to gain happiness.

Second, the teacher, as a profession, should be understood correctly. The teacher is an ordinary person, and their ability is limited. Education is not everything, and teachers themselves can't take all of the responsibility of child education. Educating children is the result of a variety of factors, not only the teachers' work. So society, schools and parents should have accurate understanding and reasonable expectations about teachers, spend more time in children education, and reduce the teachers' burden.

Third, improve the teachers' income and social status gradually. If teachers' basic life needs cannot be met, they can't educate children, let alone professional happiness. Therefore, to improve preschool teachers' professional happiness needs social valuing preschool education and raising the social status of kindergarten teachers.

\section{B. Increase the Number of Kindergarten Teachers to Make "the Proportion between Teachers and Students" More Reasonable}

Unreasonable "the proportion between teachers and students" makes it impossible for teachers to take care of every child, and it increases teachers' workload. Teachers are easy to have great psychological pressure, lose enthusiasm, and doubt their own professional value. Therefore, we should take various measures to increase the number of kindergarten teachers, make "the proportion" rational, and reduce the burden and pressure. These are strong measures to enhance kindergarten teachers' sense of professional happiness.

The proportion between teachers and students are related to the education quality closely. Teaching administrative department should pay special attention to the implement of policies, be sure the proportion is rational in the system and management. At present, on the surface the proportion is in conformity with the State provisions, but in practice the staff arrangement is not rational. Too much persons are "off-job" - they aren't engaged in teaching, and some are "middle-level managers", some are "teaching research staff", and some are "teaching assistants, etc. Which directly resulted in the proportion between teachers engaged in caring and teaching and students is too high. Some foreign countries' laws stipulate explicitly that "in the children's activity, the proportion of teachers and children can't $n$ exceed 1 to several" (Generally it is one thirteenth). Such regulation reflects the child-centered educational ideology, eliminates the inefficiencies in the system, and ensures children's and also teachers' basic rights. In the future, in our country, such provisions should also be used in the statement about the proportion between teachers and children.

\section{Do Total Home Education Well and Strive for the Support and Understanding of Parents}

Preschool education cannot develop without parents' careful care and education, especially kindergarten teacher's. Kindergarten teachers are the enlightenment to children and the first ones who guarantee children to grow healthily. Children are young and ignorant. They need not only the teachers' careful and patient care but also the teachers' subtle influence and education. They cultivate their good health habits, inspire their learning interests and hobbies, and promote their healthy overall development. Therefore, parents should understand correctly preschool teachers' job. They shouldn't consider the teachers as baby-sisters and persons who only amuse children and play games with them. That idea is disrespect toward kindergarten teachers. Parents should change their ideas. Communicate with the teachers timely, and share the good experience with other parents and teachers. They should understand the purpose of teachers' work and the teacher's hard work, and don't have too much request to teachers, and show the empathy.

Parents' support, cooperation and understanding have a positive effect on the cultivation of the teachers' professional happiness. Teachers should change the concept and communicate with parents equally. Parents should not be put on the position of a "helper", but the "cooperator" and "participant". The teacher should consider the needs of parents and their ideas, convey their 
goals and demands of their activities to the parents, mobilize the enthusiasm of parents' to participate in education, and carry out various forms of activities to enable parents to understand children's life in kindergarten, let parents feel comfortable and secured. In this way teachers can obtain parents' trust and support.

\section{Improve the Professional Level of Kindergarten Teachers}

To enhance the sense of professional happiness, the teachers should have the right professional cognition, a higher professional quality, a wealth of experience, and the competence for the work. So, the kindergarten teachers should start from their own, transform the work styles, and improve art of education and educational skills. These are important ways to enhance the sense of professional happiness.

First of all, treat children with an eye of appreciation, look for the flash and cute points in them, and try to be a happy preschool teacher. Children education process itself is a kind of enjoyment. Teachers should observe children with full heart, teach them with love, and don't simply take the education as a means of making a living. We should learn more advantages of children, be devoted to preschool education full of novelty and passion without regret every day, and carry out teaching work creatively. Secondly, work with a positive attitude and pleasant mood. They should understand and forgive children if they are naughty and headstrong, respect the personal wishes of the children, be good at transform the negative into positive situation, guide students positively and patiently; finally, communicate with children in a in faithful and friendly way. The characteristics of children determine their active, ignorant tone of command and serious expression will put a strain on the relationship between teachers and students. Squat down, listen to the child's voice, sing and dance together with children, grow with them, and we can find happiness is all around us.

In addition, in the crease of the degree of preschool teachers' specialization need preschool teachers to carry out the education action research. In the third chapter of The kindergarten Teachers' Professional Standard (trial) advocates the kindergarten teachers to study hard and make greater progress; and through continuous learning and research improve their quality, promote teacher professional development, and improve professional happiness index. Therefore, preschool teachers should have the courage to dare to get into preschool education research, feel urgently the necessity and mission of preschool education reform, solve problems existing in the practical work actively, and select targeted problem to research as a subject. Happiness is the power of teachers' professional development, is also the end-result of it. Only when they start from the need of happiness only when teachers and promote the professional ability actively can teachers experience the true happiness in the process of self-development and breakthrough.

\section{E. Create a Positive and Relaxed Working Atmosphere}

Promoting preschool teachers' professional happiness need kindergartens to create a pleasant working environment for teachers, pay attention to their personalization, and meet their reasonable demand. The formation of the pleasant environment is not separated from the director's leadership that is full of humanity. The director should discipline himself, be honest and diligent, be righteous and upright, and act as a model. He should often organize various forms of cultural activities, which can make the teachers' physical and mental relaxed after the work, increase the emotion between teachers, and deepen the affection between teachers and kindergartens. Director should also give an objective and fair evaluation to teachers and be reasonable and fair in meeting with rewards and punishments.

Kindergartens should aim at creating a relaxed and happy atmosphere, establishing harmonious interpersonal relationships, building a sunshine team, breeding sunshine children. They should actively create a harmonious atmosphere in the management, make teachers work in a positive atmosphere, praise the merits of the teachers, arouse their working enthusiasm, and let them feel the happiness brought by work.

In summary, kindergarten teachers' sense of well-being affects the quality and effect of education and the kindergarten teachers' team construction. Improving preschool teachers' professional happiness needs not only the support and attention from society and kindergartens but also the teacher's great effort. Only in this way can we make kindergarten teachers gain stronger professional well-being.

\section{REFERENCES}

[1] Ye Lan. New Analysis of Teachers' Role and Development [M] . Beijing: Education Science Press, 2001.

[2] Shu Congmin, Yao Guorong. Investigation and Consideration on the Reason of the Professional Happiness of Kindergarten Teachers [J. ] . Preschool education research, 2003 (6).

[3] Mu Ling. The Factors That Influence Teachers' Happiness and the Ways to Improve It [J. Health vocational education, 2008 (1).

[4] Shu Congmin. The Research on the Occupational Happiness of Kindergarten Teachers [D. Nanjing Normal University, 2003.

[5]Leiyan. A Study on the Subjective Well--being of Kindergarten Teachers and its Influencing Factors [ D ] .Southwestern University. 2006.

[6] xu Shasha. The Research about Preschool Teachers' Subjective Wellbeing and Social Support Relationship [D]. He'nanUniversity. 2011.5.

[7] Li Pan. Research on the Present Early Childhood Teachers' Flow in He'nan Province-- Based on the Perspective of Teacher Motivation [D]. University of henan. 2011.5.

[8] Zhang Guishi. Research on the relationship between psychological work environment and job burnout of Middle school teachers [D]. Nanchang University. 2011.12.

[9] Ma Guangrong. Research on preschool teachers' professional happiness in Weishan County [D]. Qufu Normal University, 2014.

[10] Yuan Wensheng. Teachers' wages and social status should be further improved [J]. Teaching and Educating, 2009 (9).

[11] Ministry of Education: Preschool Education Three Years' Plan , [M]. Nanjing: JiangSu Educational Press, 2000, (11) : 118-126.

[12] Liu Cilin. Analysis of Happy Education, [M]. Beijing: People's Educational Press, 2003 (6): 44-45.

[13]Pang Lijuan. The New Outline and Preschool Teachers' Professional Quality [M]. Nanjing: Jiangsu Educational Press, 2002:33-39.

[14] Peng Wenxiao. Brief Analysis of Happy Education [J]. China's Adult Education, 2006, (3): 22.

[15]Chen Yanhua. Discuss on Teachers' Happiness [J]. The Proceedings of Jinan University, 2003, (13): 1.

[16] Zeng Jia. Review of Subjective Well-Being Research [J]. The Proceedings of Xi 'an Political College, 2008 (2): 55-58. 
[17] Tan Chuanbao.Discuss on Teachers' Happiness [J]. Education Science, 2002, (2) : 3637 .

[18] Cao Junjun. Comments on Teachers' Happiness Pursuit [J]. Teacher Education Research, 2006, (9): 15 to 16.
[19] Yang Wanqiu.The Research of Primary and secondary school teachers' Subjective Well-Being [J]. Health Psychology, 2003, 11 (4): 24.

[20] Shen Yi, Wang Weihong. Preschool Teachers' Professional Development $[\mathrm{M}]$. Chongqing: Southwest Normal University Press, 2009:37 